Estuarine, Coastal and Shelf Science

December 2016, Volume 182, Part B, Pages 310-317

http://dx.doi.org/10.1016/j.ecss.2015.10.027

http://archimer.ifremer.fr/doc/00288/39918/

(C) 2015 Elsevier Ltd. All rights reserved.

\title{
Is sustainable development a motor or a constraint for the professionalization of the pearl oyster industry in tahiti?
}

\author{
Rey-Valette Hélène ${ }^{1}$, Lacoste Élise ${ }^{1,{ }^{*}}$, Perez Jose ${ }^{2}$, Raux Pascal ${ }^{3}$, Gaertner Jean-Claude ${ }^{4}$, \\ Gaertner-Mazouni Nabila ${ }^{5}$
}

${ }^{1}$ Centre National de la Recherche Scientifique (CNRS), Université Montpellier 1, UMR 5474 LAMETA,

France

2 Ifremer, UMR M101 AMURE, France

${ }^{3}$ Université de Brest, UMR M101 AMURE, France

${ }^{4}$ Institut de recherche pour le développement (IRD), UMR $241 \mathrm{EIO}$, Polynésie française

${ }^{5}$ Université de Polynésie française, UMR 241 EIO, Polynésie française

* Corresponding author : Elise Lacoste, email address : eliz.lacoste@gmail.com

\begin{abstract}
:
This article reports the results of a survey of the pearl oyster industry in French Polynesia territory. Its purpose is to examine the perceptions of the priorities for the development of this industry towards sustainable development. These perceptions were apprehended by a survey of pearl oyster farmers and other stakeholders of the sector (management authorities, scientists). After describing the methodological protocol of these investigations, it comes to confront the priorities chosen by professionals (i.e. pearl farmers) concerning sustainable development, with the perceptions of others stakeholders in the sector. Secondly it comes to build a typology of the priorities of pearl farmers concerning sustainable development. This analysis enables the assessment of the degree of convergence within the sector, which is the base material for defining a shared action plan at the territory scale. This is the first study compiling data of surveys of various professionals and stakeholders of the pearl farming industry in such a large area in French Polynesia.
\end{abstract}

Keywords : Sustainable development, pearl oyster farming, perceptions, collective learning process, indicators, French Polynesia 


\section{Introduction}

Island territories have their own specific economic dynamics, not simply because of the constraints in the spatial distribution of services and facilities but also because of the greater interaction between local communities and shoreline and marine ecosystems (Douglas 2006). In addition to the heritage and cultural significance of the Polynesian coral reef ecosystems, their transition towards sustainable development and towards respect for carrying capacity has become a priority on account of their high level of vulnerability. These objectives are however difficult to achieve because of the sheer scale and dispersal of the territories. One must bear in mind that French Polynesia is comprised of 118 island and atolls for a total surface area of 5 million $\mathrm{km}^{2}$ of which $3500 \mathrm{~km}^{2}$ of emerged lands inhabited by a population of 270000 (Merceron, 2014). We examine the pearl oyster farming industry which has experienced considerable development since the 1970's with the number of farms rising from 16 to 980 between the 1980's and 2000.

Today the activity is carried out on 25 islands mainly in the Tuamotu Archipelago. Second source of income after tourism and first item of exportation (66\%), the sector plays a vital economic role representing 65 million euros in 2013 (Talvard, 2015). This is equivalent to the total income associated with exportation of edible oysters in France in 2014 (FranceAgriMer, 2015). In addition to job creation on the atolls, it also greatly influences land-use management by reducing human migratory flows towards Tahiti (Tisdell and Poirine, 2000). In the 2012 census, 1300 people were employed in the sector (Talvard, 2015). The evolution of grafting and husbandry techniques has greatly contributed to production development. The number of farms has increased from 16 to 900 between the 1980's and 2000 and the exports rose from $200 \mathrm{~kg}$ in 1987 to around 15.5 tonnes in 2013 (Talvard, 2015). Growth in production has however been accompanied by a fall in the quality and competitiveness of Polynesian products (Raux and Bailly, 2000). Tahitian pearls are in competition in the world market with new countries producing pearls at low price (e.g. Chinese 
price for pearls and brought about numerous bankruptcies. In 2013, only 517 farms remained (Talvard, 2015), 77\% of which are located in the Tuamotu Archipelago (Fig. 1). In this context, regulation of overproduction and restructuring are now considered necessities. It is within this framework that the interdisciplinary research programme POLYPERL (ANR-Agrobiosphère) has been set up. Managed conjointly with government authorities (Service de la Perliculture), its aim is to develop an integrated strategy to identify pertinent and legitimate measures for professionals of the sector.

For restructuring to be effective however, it should not be limited simply to improving technical or economic performance but should integrate sustainable development issues more broadly to strengthen the resilience of the sector and the local economy of the atolls. These objectives require a change of frame of reference, i.e. an overhaul not just of everyday practices but of values and perceptions. This means going beyond simply increasing awareness through information campaigns towards implementing individual and group training programmes (Argyris and Schön, 1996; Akrich et al., 2006). To define objectives that are both familiar and easily appropriated by professionals of the sector, it is important to take into account the perceptions they have of the priorities for sustainability and to associate them with the creation of a new frame of reference for their sector (Reed et al., 2008; Fraser et al., 2006; Jolland and Harmsworth, 2007). These specific conditions lead us to recommend that the introduction of sustainability objectives for the Tahitian pearl farming industry proceed from a co-constructed approach based upon development principles that professionals and stakeholders consider as priorities. We have therefore set up a joint construction of indicators for the pearl farming industry through a survey aiming to create a hierarchy of sustainable principles which professionals and stakeholders consider as priorities. These principles are defined by taking into account the institutional dimension so as to identify the processes by which organizational innovation is capable of implementing sustainable development. This aspect of sustainability is crucial in the particular institutional context of French Polynesia where the issue of local autonomy in public policies and its relationship to doctrines defined by the State in 
approach, the aim is to understand not only the sustainability of the sector but also the contribution to the sustainability of the territories in the atolls where this activity is carried out. Acknowledging the territorial dimension is important in strengthening the social and institutional integration of the activity, especially where it points up the diversity of ecosystem services it offers (Millennium Ecosystem Assessment, 2005).

The aim of this article is to give an account both of the procedures of identification and the benefit of the principles of sustainable development in order to make the strategy of integrated and sustainable management more acceptable. Acknowledging the perceptions of professionals and stakeholders reinforces both the effectiveness and legitimacy of public policies. It also enables a definition of the measures to be taken which will encourage individual and group learning programmes to foster a common conception of sustainable development. In the Polynesian context, it is important to recognize the cultural particularities of its relationship to nature (Descola, 2005), the major names in Polynesian identity and the inadequacy of collective perceptions of 'long time' which require the process of learning and appropriating specific policies of sustainable development (Ghasarian et al., 2004).

In the first part, we shall specify the logic and methodology of the survey which aim to identify the perceptions of sustainability by stakeholders and professionals of the pearl farming industry within the Polynesian context. The second part will present the results, i.e. the perceptions and constraints of the activity and of sustainable development. These will be followed by a discussion on the benefit of these results for implementing sustainable management within the pearl farming industry in French Polynesia.

\section{Methodology}

\subsection{Acknowledging perceptions of sustainability for sustainable management of the sector}


construction of a system of indicators which then constitutes a means of mediation enabling appropriation of the objectives of sustainable development (Rey-Valette et al., 2007; Mazouni and Rey-Valette, 2008; Rey-Valette et al., 2010; Levrel et al., 2009; Lazard et al., 2014). Beyond their measuring function, indicators constitute intermediate 'mediators' as defined by Vink (2000) thus facilitating the implementation of sustainability. Discussion on the principles and even the criteria of sustainability are a form of collective learning which allows appropriation of the new value system which sustainable development represents. Its intention is to promote a procedural, adaptive and participatory strategy defined as 'principle-guided' (Rey-Valette et al., 2008; Lazard et al., 2014) which interlocks principles, criteria and indicators. The indicators could be constructed once the perceptions of sustainable development have been identified. In this paper, we do not develop the connection between the perceptions and the indicators but focus on the implementation of a specific methodology in the context of French Polynesia, to identify the priorities in term of sustainable development. The first stage was thus to identify the principles or objectives which make sense to pearl farmers and stakeholders. This stage is decisive since it acknowledges the diversity of the perceptions of sustainable development. Moreover, it corresponds to an approach by 'milestone' (instead of dimension) as it is recommended by the national strategy of sustainable development in France (MEDDE 2013). The originality of our approach is to have designed a specific survey for French Polynesia. It was in fact impossible to ask the farmers and stakeholders freely and directly about their conception of sustainability since the term of sustainable development is foreign to the local culture. Preparatory groundwork with our local partners had identified 6 key principles (Table 2, 3) for each dimension of sustainable development which the respondents were invited to select and grade. To facilitate the grading, we built a set of illustrated cards (Fig. 1) representing the different principles that the stakeholders and professionals could choose as priorities. Among the 6 cards, the respondents had to select two which they considered priorities for sustainable development. On the whole, these exchanges went off well with a non- 
$15 \%$ for the environmental and social dimensions).
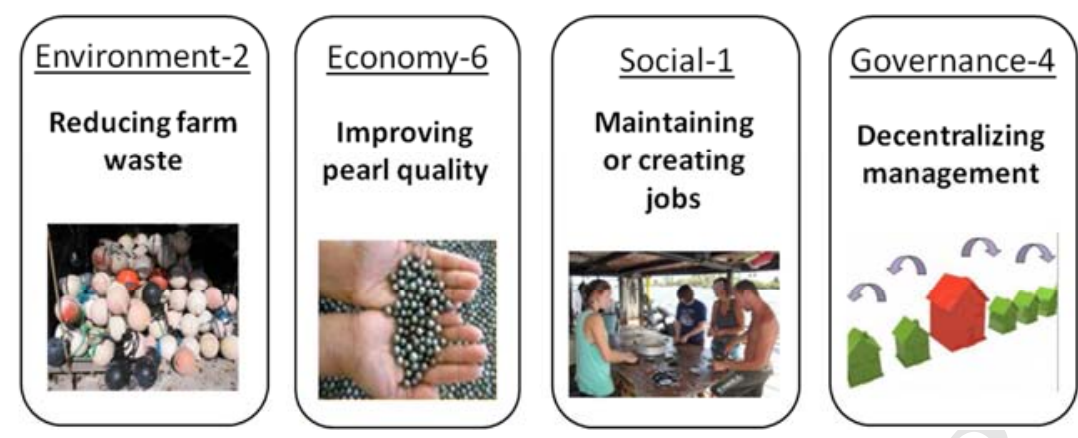

Figure 1. Example of illustrated cards representing principles identified for each dimension of sustainable development. Each dimension include 6 principles represented on 6 cards.

\subsection{Study protocol and procedures at the scale of the Tahiti pearl farming industry}

A study of farmers and stakeholders was carried out in 2013 (Table 1) in order to characterize the farms and to identify the perceptions of sustainable development. The farmers underwent a survey of situation studying their structure (e.g. origin of pearl farmers, farms' history), operating costs (e.g. number of employees, investment, marketing) and also the issues of industry, the nature of their links to the sector and the territory as well as the constraints encountered. Finally, their perceptions of sustainability were discussed using the set of illustrated cards. A sample of farms was selected that represented the diversity of operating sites (Fig. 2). The procedures had to take into account the fact that the farmers' databases, which are managed by the government department of pearl farming, did not enable an accurate depiction of certain farms. In this period of crisis, the sector is characterized by job diversification where farms may remain 'dormant' for several months. Furthermore, the farms are widely scattered and on certain sites beset by frequent telephone connection problems. We conducted a cluster survey by first selecting atolls that were representative of the sector and then, once we were on site, drawing up a list of professionals to be used for the study whilst also considering the difficulty of access to their sites. In all, the number of farmers in the survey represents between $10 \%$ and $36 \%$ of the total number of pearl farmers depending upon the type of farm (Fig. 2). This first survey was followed up by a second of the 
and in total 24 people were surveyed.

Finally, the variables and principles considered as priorities during these two surveys were discussed and graded at a workshop held on 22 May 2014 in Tahiti. The group consisted of 20 people ( 7 scientists from different fields, 10 stakeholders from downstream activities (sales group, retailers, jewellers) and 3 institutional stakeholders in charge of managing the sector including the Minister for Marine Resources. The participants were asked to select from among the principles valued as important during the surveys those they considered as priorities.

Table 1. Characteristics of the surveys conducted

\begin{tabular}{|c|c|c|}
\hline & Survey of pearl farmers & Survey of stakeholders \\
\hline Numbers surveyed & 93 & $24^{*}$ \\
\hline Area & $\begin{array}{l}5 \text { of the main atolls involved in pearl } \\
\text { farming }\end{array}$ & Tahiti \\
\hline Place & At their homes or on the farms & At their workplaces \\
\hline Length of time & 60 to 90 minutes & 45 to 60 minutes \\
\hline Period & April \& July 2013 & May to August 2013 \\
\hline Type & $\begin{array}{l}\text { A majority of closed-ended questions }+ \\
\text { cards on sustainable development }\end{array}$ & $\begin{array}{l}\text { Interview guide consisting mainly of open-ended } \\
\text { questions + cards on sustainable development }\end{array}$ \\
\hline Sample & $\begin{array}{c}\text { Cluster method aiming to sample firstly } \\
\text { the atolls then the operating quotas per } \\
\text { atoll }\end{array}$ & $\begin{array}{l}\text { Purposive sampling of the main stakeholders } \\
\text { with a balance between institutional and } \\
\text { economic actors }\end{array}$ \\
\hline
\end{tabular}

11 institutional stakeholders (local politicians, marine resources management, a training organization, marketing associations, environment associations and research organizations) and 13 economic stakeholders (Maison de la Perle, bank, suppliers, dealers, craftsmen and jewellers). 


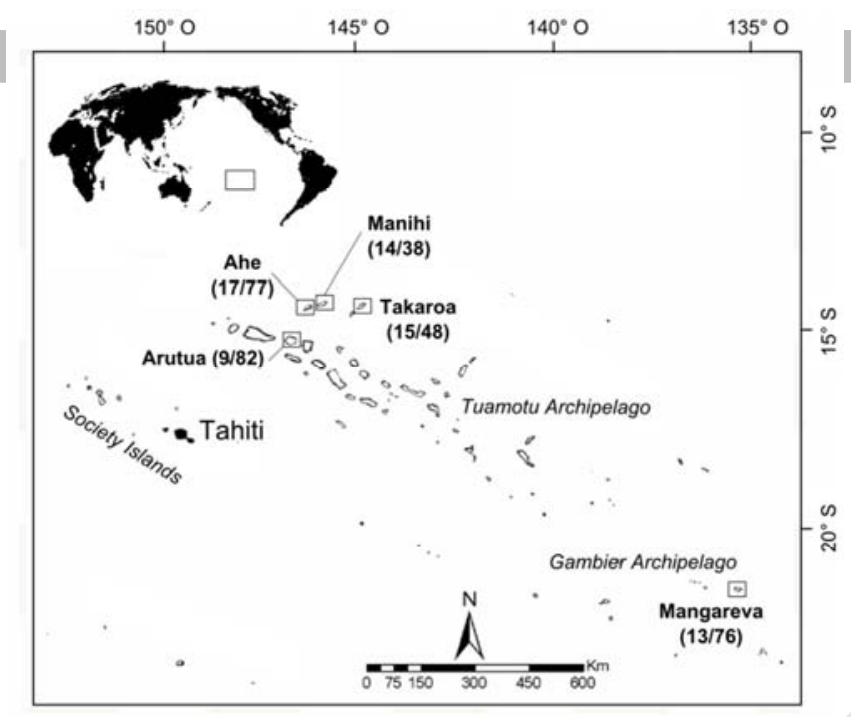

Figure 2. Location and numbers of pearl farmers surveyed at various atolls (numbers surveyed $/$ total $n^{\circ}$ of farms on the atoll according to the French Regional Office for Marine Resources)

\subsection{Multivariate analysis of results to establish a typology among pearl farmers of perceptions of sustainable development}

Firstly, systematic cross tabulation (chi square tests²) was made to identify possible correspondences between perceptions of sustainable development among pearl farmers and socioeconomic (or structural) variables (e.g. size of farms, atoll, membership of a marketing association). Secondly, we sought to build a typology of sustainable development perceptions from a Multiple Correspondence Analysis (MCA, Abdi and Valentin, 2007). This type of analysis enables identification of archetypes, in the Weberian understanding of ideal-type categories (Weber, 1992; Schnapper, 1996) which indicate meta-perceptions depending on the recurrence of associations between the various principles of sustainable development. In view of the numbers surveyed and statistical demands, we had to reduce the principles (24) by grouping the principles two by two in each dimension according to close thematic links (Table 2). Principles referring to a similar idea were grouped to describe larger concept (e.g. 'Preserving landscape' and 'Reducing farm waste' correspond to an idea of respect of the environment), coded with letters from A to L. Finally, 12 principles were kept for the MCA, i.e. 3 per dimension of sustainable development. Analysis was carried out using the R software ( $\mathrm{R}$ development core team, 2014). 
Table 2. Grouping of sustainable development principles for the multiple correspondence analysis (MCA) (n: total numbers of choices after grouping)

\begin{tabular}{|c|c|c|c|}
\hline Principles & Code (n) & Principles & Code (n) \\
\hline Environment & & Social & \\
\hline $\begin{array}{l}\text { Preserving landscape } \\
\text { Reducing farm waste }\end{array}$ & Env.A (36) & $\begin{array}{l}\text { Maintaining or creating jobs on the atolls } \\
\text { Income stability }\end{array}$ & Soc.G (37) \\
\hline $\begin{array}{l}\text { Biofouling management } \\
\text { Use of non chemical nucleus }{ }^{\text {II }}\end{array}$ & Env.B (14) & $\begin{array}{l}\text { Strengthening bonds between professionals } \\
\text { Developing training }\end{array}$ & Soc.H (10) \\
\hline $\begin{array}{l}\text { Monitoring lagoon quality (water) } \\
\text { Monitoring of diseases }\end{array}$ & Env.C (23) & $\begin{array}{l}\text { Attachment to the profession } \\
\text { Maintaining families on the atolls }\end{array}$ & Soc.I (26) \\
\hline Economy & & Governance & \\
\hline $\begin{array}{l}\text { Increasing profits } \\
\text { Facilitating credit access }\end{array}$ & Eco.D (19) & $\begin{array}{l}\text { Strengthening regulation } \\
\text { Reinforcing inspections }\end{array}$ & Gouv.J (20) \\
\hline $\begin{array}{l}\text { Introducing production quotas } \\
\text { Market regulation }\end{array}$ & Eco.E (32) & $\begin{array}{l}\text { Participation of professionals in management } \\
\text { Increasing access to expertise }\end{array}$ & $\begin{array}{l}\text { Gouv.K } \\
(17)\end{array}$ \\
\hline $\begin{array}{l}\text { Developing sales campaigns } \\
\text { Improving pearl quality }\end{array}$ & Eco.F (22) & $\begin{array}{l}\text { Facilitating transfer to children } \\
\text { Decentralizing management }\end{array}$ & $\begin{array}{l}\text { Gouv.L } \\
(36)\end{array}$ \\
\hline
\end{tabular}

"Nucleus is a spherical shell beads introduced in pearl oysters to produce round pearls

\section{Results}

\subsection{Perceptions of the profession and the constraints encountered}

Interviewed about their global perceptions of pearl farming, two thirds of professionals (65\%) point to local job creation. For their part, stakeholders highlight the maintaining of population numbers on the atolls (32\%) and the source of income (29\%). Figure 3 enables a more precise analysis of the perceptions pearl farmers have of their profession. They were asked about professional satisfaction in relation to several points for which they had to reply either by 'yes' or 'no' each time. Figure 3 presents the proportion of positive responses for each item. The majority of professionals agree that it is a profession which allows them to remain on the atolls but also involves a risk of accidents (>70\%). Nearly two thirds mention its physical demands, the length of working hours and the financial risks. Lastly, pearl farmers are more divided over the importance of financial expenses and the possibility of generating high profit. 


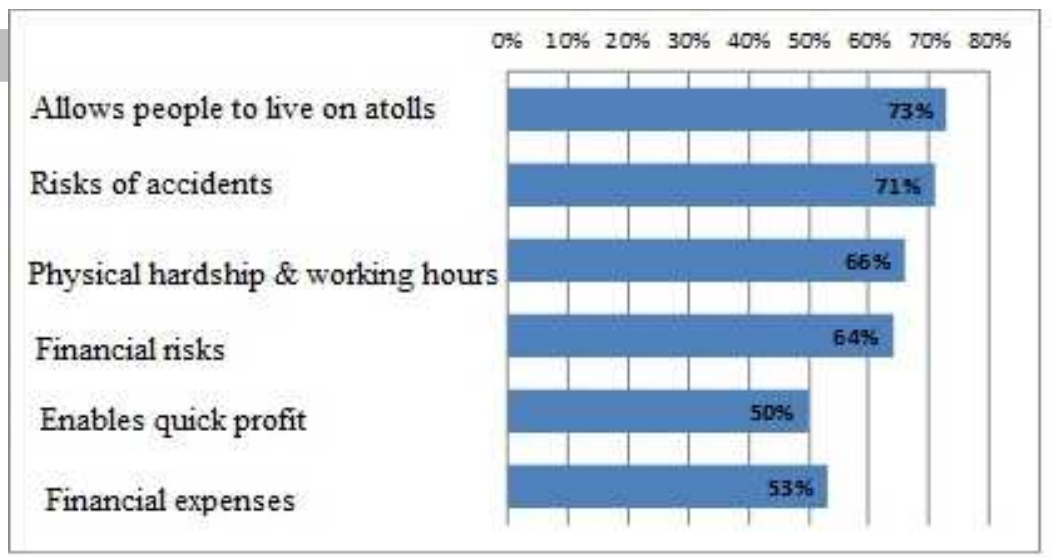

Figure 3. Pearl farmers perceptions of their profession (\% of positive responses)

Professionals were also asked about the constraints they faced in order to identify those which could be removed by sustainable management of the sector. The questions concerned several constraints for which professionals were asked whether they constituted 1) no or 2) low constraints or, on the contrary, 3) high or 4) very high constraints. Figure 4 presents the cumulative percentages of 'high' and 'very high' responses. The two main constraints for pearl farmers are the competition between producers and difficulty of access to expertise. Environmental constraints are also often cited: $77 \%$ of professionals mention sensitivity to disease and $68 \%$ environmental quality. In contrast, predation and market constraints were considered as 'high' or 'very high' by less than $30 \%$ of farmers.

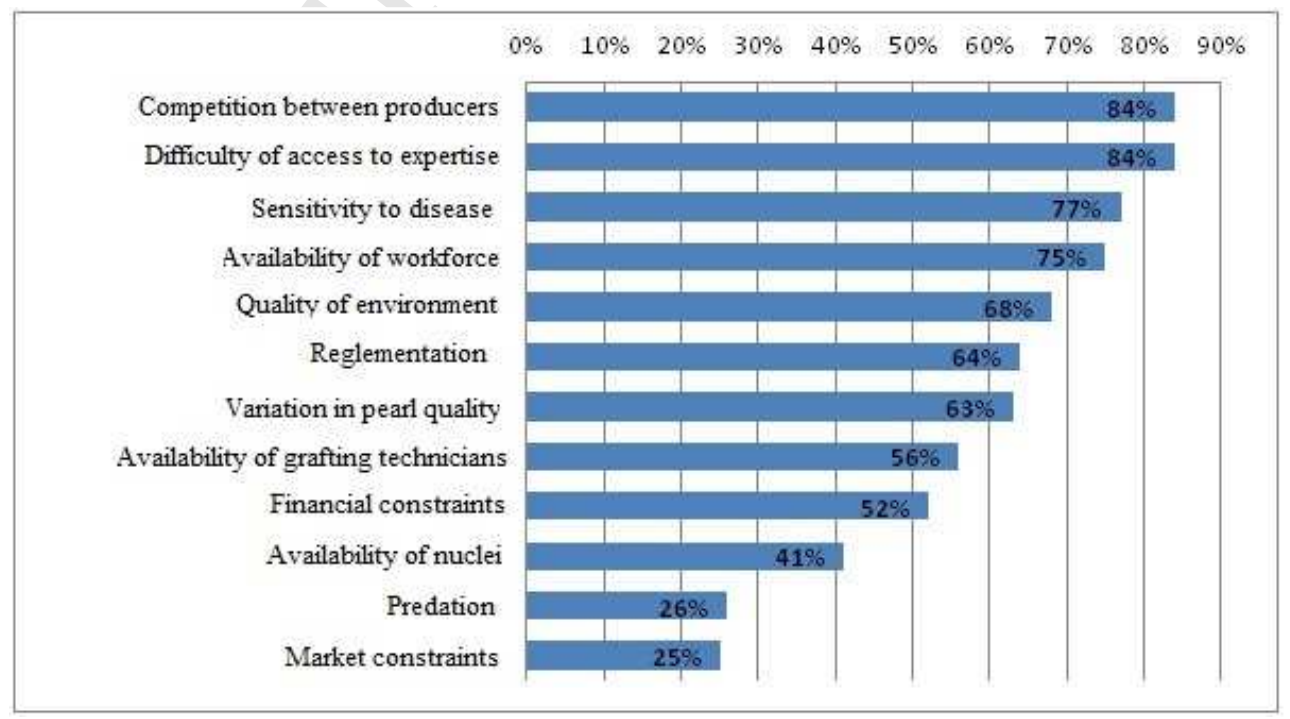

Figure 4. Perception of constraints in their profession by pearl farmers

(\% of 'high' or 'very high' responses) 
Finally, the questionnaire dealt with prospects for the activity, especially strategies that

professionals envisaged in the case of a crisis. It is important to note that in the event of a crisis, half $(53 \%)$ of the respondents stated that they would maintain their activity and roughly a third (37\%) opted for a strategy of diversification.

\subsection{Perceptions of sustainable development}

The wide variation in development principles selected points up important differences between the two categories of respondents (i.e. farmers and stakeholders) regarding the environmental and institutional dimensions (Table 3). For the environmental aspects, the farmers insist more upon the preservation of the quality of the atolls (preserving landscapes and reducing waste) whereas the stakeholders are more sensitive to the monitoring of the quality of lagoons and stocks (monitoring diseases). For the institutional aspect (i.e. governance), the stakeholders insist upon the participation of professionals in management whilst the latter are more sensitive to the possibility of passing on their profession to their children and also to the decentralization of management. For the economy, it is the aspects concerning regulation by quotas and the quality of the products which are highlighted by both categories, stakeholders also insisting on market regulation and publicity campaigns for products. Finally, for the social aspect, the role of land-use management by job creation on the atolls is praised by farmers and stakeholders alike, with attachment to the profession and maintaining families on the atolls arriving in second place respectively. 
Table 3. Synthesis of the principles selected for each dimension of Sustainable Development

\section{Environment}

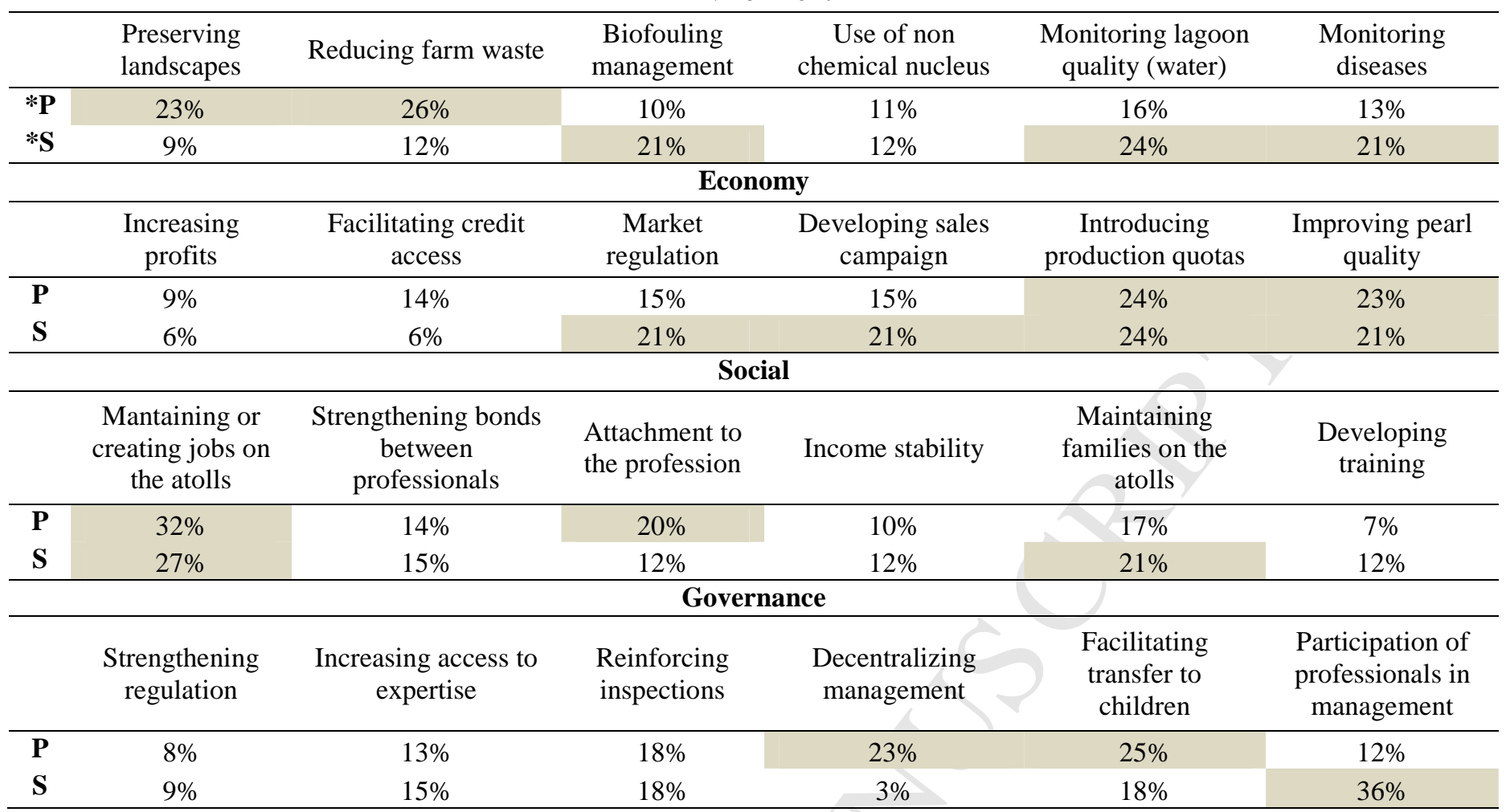

${ }^{*} \mathrm{P}=$ Pearl farmers (total of choices 1 and 2 as $\%$ of total) $; \mathrm{S}=$ Stakeholders (total of choices 1 and 2 as $\%$ of total)

The most chosen principles (> 20\%) are shaded

\subsection{Cross-tabulating the principles of sustainable development with socio-economic variables}

The search for correlations between the main structural variables of farmers (age, years in profession, farmer's local origin) and farms (atoll, size, membership of marketing association) and the choice of sustainable development principles only produced a small number of significant relations (5\% threshold). For individual factors, it is essentially the professional's age and origin (born or not on the atoll where he works) which have an influence, whilst for the farms only size counts. Perceptions of the profession, whether it be the role of pearl farming in land-use management (maintaining population levels on the atolls), in the economy (private activity) or in social issues (shared activity), do not influence the choices of sustainable development. However perceptions of the role of the activity are linked to age $(X=12.17, \mathrm{df}=4, \mathrm{p}<0.05)$. We can see a preference among the young for its role as a shared activity, among middle-aged professionals for its role in employment whereas in the above 50 age group it is most often the economic role which is highlighted. 
development. Environmental objectives are linked to the question of whether the farmer is or is not from the atoll where his farm is located $(\mathrm{X}=12.96, \mathrm{df}=5, p<0.05)$ as well as to the size of the farm $((X=24.33, \mathrm{df}=10, p<0.01)$. Farmers who are not from the atoll where they work tend to choose waste reduction in first place and biofouling management in second position. Those who are from the atoll where they work favour the use of non-chemical nuclei and the monitoring of water quality. Smaller farms tend to emphasize preserving landscapes whereas the bigger farms are more concerned with monitoring diseases. As for governance, there is only a relation to age $(\mathrm{X}=24.11$, $\mathrm{df}=12, p<0.05)$ : the more older farmers $(>50$ years) being in favour of reinforcing inspections, middle-aged farmers (40 to 50 years) preferring participation in management and the younger group more interested in facilitating the handing down of their farms to their children. The social and economic principles are not linked to any of the structural variables surveyed.

\subsection{Typology of perception by multiple correspondence analysis}

MCA was used to identify potential patterns of professionals regarding the principles of sustainable development. This analysis carried out on the grouped principles of sustainable development (Table 2) enables us to identify three major archetypes or groups of individuals (Fig. 5). As in general for factorial analysis, MCA is not intended to precisely delimitate the groups, but to evidence general trends relative to sustainable development principles. In our case, the groups indicate synthetic profiles for the priorities identified as leading to sustainable development in pearl farming. 


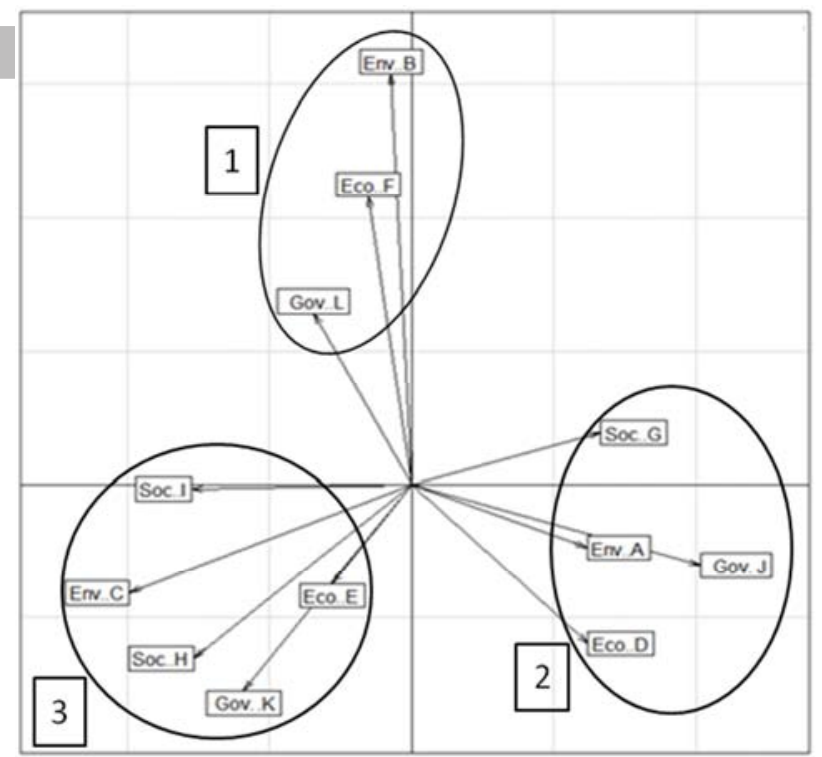

Figure 5. Projection of the grouped principles of sustainable development ( $c f$ Table 2) chosen by pearl farmers on the first plan of the MCA (multiple correspondence analysis) (axis 1: 20\%; axes 2: 18\%).

1. The first group ([1]) favours the adoption of sustainable practices through biofouling management and the use of non chemical nucleus, a strategy based on quality and campaigning, and finally the decentralization of management and transfer to children.

2. The second group ([2]) is more sensitive to maintaining landscapes and waste management, which corresponds to the more land-orientated environmental approach of sustainable development. In this group, farmers are also sensitive to the cost efficiency of units (increasing profits and access to credit), to job and income creation on the atolls and to reinforcing inspections and regulation.

3. Lastly, the third group ([3]) favours the monitoring of lagoon quality and diseases, the introduction of quotas and market regulation. This group would also like to see strengthening of bonds between professionals, more training and greater participation in management.

Groups 1, 2 and 3 have respective totals of 14, 29 and 24 pearl farmers. Groups 2 and 3 include the principles of each dimension of sustainable development while in group 1, the social dimension does not appear. It is however strongly represented in group 3, thereby distinguishing it from group 
marketing association or the age of the farmers are spread evenly over the three groups and do not allow to link the perceptions with the socio-economic structure of farms.

\section{Discussion}

\subsection{Confirmation of the benefit of a co-constructed approach}

The policy recommendations of Agenda 21 in Rio, the methodology or strategy documents which followed and the work carried out on implementation of sustainable development policies all insist on their collaborative dimension, especially in defining goals which determine policy choices at a territorial or sector level. Participatory approaches often schedule consultation stages in their process (Mendoza and Prabhu, 2000; King et al., 2000; Antunes et al. 2006). In the case of Polynesia, the scale of the territory, the dispersal of the pearl farms and the diversity of production systems constituted considerable constraints on mobilizing a focus group among the farmers. However, the stakeholders did have representative bodies in Papeete, thereby enabling us to gather a wide variety of viewpoints efficiently. The benefit of a survey of perceptions is confirmed in the environmental issues. To improve acceptance of conservation measures there has to be assessment of the awareness of ecosystem services and the impact on community well-being (Kaplowitz and Hoehn, 2001; Fontana et al. 2013). Taking perceptions into account enables assessment of the environmental sensitivity of individuals, a more consensual definition of sustainable projects and also facilitates collective discussion and engagement in the common good (Thompson and Stoutermeyer, 1991).

It is also necessary to go beyond individual perceptions to an examination of collective perceptions at territory or network levels (Jones et al., 2012). In the case of ecosystem services, perceptions may reflect scales (Hauck et al., 2013) or types of stakeholders (Hein et al., 2006). In this survey, the differences between pearl farmers and stakeholders are minor. Similarly, we noted in the focus groups a high concentration of choices upon a small number of principles, which were also selected 
geographic dispersal of perceptions are assets for creating a collective dynamic at the scale of the sector and for improving governance (Lewan and Söderqvist, 2002 ; O’Connor et al., 2003; Pavlikakis and Tsihrintzis, 2003).

Finally, concerning the benefit of our approach, let us underline the fact that the discussion created by the selection of sustainable development cards was itself a first step in favour of the understanding and acquisition of the notion of sustainability (Fraser et al., 2006), the latter not being deeply rooted in Polynesian culture which tends to favour the short term. Martinez de Anguita et al., (2008) emphasize the fact that the framework for individual decision-making involves values that are larger than those highlighted by sustainability and that its acceptance can only proceed from larger philosophical systems used to guide people's lives, most notably in their relationship to the environment and to the land. It is in this sense that providing support and heightening awareness constitute public policies that are increasingly important and decisive for the acquisition of the innovations implied by sustainable management of the sector (Laurans et al., 2013).

\subsection{Different strategies for the implantation of sustainable development}

The typology of the farmers' perceptions of sustainability leads us to characterize three different approaches to sustainability in the sector.

1. The first profile corresponds to a pro-active and entrepreneurial vision of sustainable development. In this particular case, sustainability may be seen as an opportunity favouring the promotion and the image of pearls. Businesses and the market are at the heart of the system and may be the vector for innovation.

2. The second profile highlights the role of land-use management in the sector but also the need for cost efficiency and increasing inspections. In this case, keeping businesses going, which means strengthening their cost efficiency and increasing supervisory control, is seen as a tool for land-use management. The relationship to the territory is the focal point and constitutes the motive for change. 
of certain units and a greater professionalization. This vision involves greater restructuring of businesses where sustainable development becomes the means to professionalizing the sector by highlighting skills and information. This derives partly from the idea that with sustainability comes greater responsibility, especially in the monitoring of impacts and a mastery of processes.

The identification of these profiles confirms the diversity of the ways in which sustainable development may be appropriated. However, this diversity of approach should not be seen as a constraint. On the contrary, it is vital to the process of appropriation. It is useful to remember that the determinants in eco-innovation are threefold: regulation, the market and/or costs associated with technology (Renning, 2000, Galliano and Nadel, 2013). These different profiles are therefore not contradictory but indicate different pathways to the adoption of new practices which are complementary, and should be presented as such in communication campaigns. Greater professionalization will, for example, reply to the constraint expressed by the majority of farmers concerning the difficulty of access to technical knowledge. In the same way, the collective restructuring of the sector will have to face the problem of market competition, a problem that has been strongly felt by the farmers. It will be all the easier to show how complementary the profiles are for their being, as the results of our approach indicate, widely distributed among professionals and not coinciding with geographic characteristics related to the atolls, social issues such as the age of farmers nor economic factors related to the size of farms. The widespread nature of viewpoints may no doubt be explained by the specific features of Polynesia which bring about a relative isolation of professionals. Only the local or non-local origin of farmers plays a role in the sense that farmers who are from the atoll where they work are more sensitive to the social dimension of sustainable development. This corresponds to the logic of local economies (Torre and Traversac, 2011) and attachment to the atoll plays a vital role in this case. Big businesses with highly mobile capital may invest in or leave an atoll according to conditions of productivity related 
mobility and a strong attachment to the atoll, express more often the need to preserve their ecosystem for themselves as well as for their children. In this instance, maintaining the ecosystem is the prerequisite for maintaining their business and the survival of their family.

\section{Conclusion}

Ever since it began, pearl farming in Polynesia has been subjected to multiple constraints that have led to various crises. Although stakeholders in the sector today underline the difficulties of the activity (e.g. accidents, physical demands), they also agree upon the positive aspects of the profession in land-use management and share a desire for continuity, especially where this maintains employment on the atolls. From surveys among farmers and stakeholders of their perceptions of the principles of sustainable development, we have identified three profiles corresponding to different but complementary perceptions of sustainability. Whilst our sample group provides a spatially representative selection, it is true that transport constraints between atolls reduced its size. Nevertheless, our results partially concur with the tacit knowledge of local researchers concerning the levers for implementing sustainable management of pearl farming. We also come across the logic behind the adoption of eco-innovations (Renning, 2000 ; Galliano and Nadel, 2013). The identification of the existence of several profiles enables us to suggest various supporting measures as well as imagining different pathways towards sustainability according to the type of group. It is not about favouring one profile over another but, on the contrary, seeking to build within the sector a common perception of sustainable development which associates all viewpoints. However the very western nature of the idea of sustainable development, even of 'development' itself, means adapting communication and awareness campaigns, as we did in designing specific cards. Not only is sustainable development ill matched with those aspects of Polynesian culture rooted in the short term but the term development when applied to a community or a sector is itself a foreign concept to Polynesians. It is always used to indicate the development of a 'thing' (e.g. a tree, a fruit). Certain respondents encountered difficulties in choosing from the 
initial method (PCI, Rey-Valette et al., 2008; Lazard et al. 2014) with the introduction of sustainable development cards. This demonstrate the flexibility of implementation of the method in different situations.

Our work does however indicate for all three profiles an acknowledgement among farmers of the need for collective regulation, which bodes well for the restructuring of the sector. Faced with a rise in production and the automatic fall of prices that ensues, the logic of farmers in the past was to increase or intensify production in order to maintain income, all of which led to overproduction, a drop in quality levels and then in the number of farms. The results of the survey show that most stakeholders including farmers are now aware of the perverse effects of this strategy. Sustainable development thus appears as an opportunity to define new approaches and to favour a restructuring of the profession. It is crucial especially for small farms to implement measures that lead to the organization of markets and the reorganization of governance, whether that be of authorities, regulatory instruments or monitoring protocols for the vulnerability of units. According to the profiles identified, certain actions will seem legitimate to professionals and so support should go to the other types of action, even if one must take into account the fact that communication and the setting-up of networking between producers to strengthen their implication in management will be heavily impeded by the geographic dispersal of the units. The efficiency therefore of governance mechanisms in issues of communication and exchange will largely determine the implementation of these new management strategies.

\section{Acknowledgements}

This study is a part of the research project "Management and adaptation of pearl culture in French Polynesia in the context of global change: an environmental, economic and social approach" (POLYPERL) funded by the French National Research Agency within the framework of the program AGROBIOSHERE (ANR-11-AGRO-006). We gratefully acknowledge the contributions of our partners in the project. 


\section{References}

Abdi H., Valentin D., 2007. Multiple correspondence analysis. In: Encyclopedia of measurement and statistics, Salkind N. (Ed.), Thousand Oaks (CA). pp. 651-657

Akrich M., Callon M., Latour B., 2006. Sociologie de la traduction. Textes fondateurs. Mines Paris, Les Presses. Collection Sciences Sociales

Al Wardi, S., 1998, Tahiti et la France : le partage du pouvoir. L'Harmattan, Paris

Antunes P., Santos R., Videira N., 2006. Participatory decision making for sustainable development — the use of mediated modelling techniques. Land Use Policy, 23(1), 44-52

Argyris C., Schön D., 1996. Organizational learning II: Theory, method and practice. Reading (Mass): Addison Wesley

Descola P., 2005. Par-delà nature et culture. Gallimard, coll. NRF, Paris, p. 628

Douglas C.H., 2006. Small island states and territories: sustainable development issues and strategies - challenges for changing islands in a changing world. Sustainable Development 14 :7580

Fontana V., Radtke A., Bossi Fedrigotti V., Tappeiner U., Tasser, Zerbe S., Buchholz T., 2013. Comparing land-use alternatives: Using the ecosystem services concept to define a multi-criteria decision analysis. Ecological Economics 93, 128-136

FranceAgriMer, 2015. Les filières pêche et aquacultures en France. Les cahiers FranceAgriMer. Avril 2015. 36p. www.franceagrimer.fr/filiere-peche-et-aquaculture/Informationseconomique/Chiffres-et-bilans.

Fraser E.D., Dougill A.J., Mabee W.E., Reed M., McAlpine, P., 2006. Bottom up and top down: Analysis of participatory processes for sustainability indicator identification as a pathway to community empowerment and sustainable environmental management. Journal of environmental management, 78(2): 114-127

Galliano D., Nadel S., 2013. Les déterminants de l'adoption de l'éco-innovation selon le profil stratégique de la firme. Le cas des firmes industrielles françaises. Revue d'éco industrielle, 142, 77110

Ghasarian C., Bambridge T., Geslin P., 2004. Le développement en question en Polynésie française. Journal de la société des océanistes 119

Hauck J., Grög C., Varjopuro R., Ratamaki O., Jax K., 2013. Benefits and limitations of the ecosystem services concept in environmental policy and decision making: Some stakeholder perspectives. Environmental Sciences \& Policy, 25, 13-21 
Hein L., van Koppen K., de Groot R.S., van Ierland E.C., 2006. Spatial scales, stakeholders and the valuation of ecosystem services. Ecological Economics. 57, 209-228

Jollands N., Harmsworth G., 2007. Participation of indigenous groups in sustainable development monitoring: Rationale and examples from New Zealand. Ecological Economics, 62(3) : 716-726

Jones N., Clark J.R.A, Panteli M., Proikaki M., Dimitrakopoulos P.G., 2012. Local social capital and the acceptance of Protected Area policies: An empirical study of two Ramsar river delta ecosystems in northern Greece. Journal of Environmental Management 96, 55-63

Kaplowitz M.D., Hoehn J.P., 2001. Do focus groups and individual interviews reveal the same information for natural resource valuation? Ecological Economics. 36, 237-247

King C., Gunton J., Freebairn D., Coutts J., Webb I., 2000. The sustainability indicator industry: where to from here? A focus group study to explore the potential of farmer participation in the development of indicators. Animal Production Science, 40(4), 631-642

Laurans Y., Rankovic A., Billé R., Pirard R. Mermet L., 2013. Use of ecosystem services economic valuation for decision making: Questioning a literature blindspot. Journal of Environmental Management, 119, 208-219

Lazard J., Rey-Valette H., Aubin J., Mathé S. et al. 2014. Assessing aquaculture sustainability: a comparative methodology. International Journal of Sustainable Development \& World Ecology, 21(6), 503-511

Levrel H., Etienne M., Kerbiriou C., Page C. L., Rouan M., 2009. Co-modeling process, negotiations, and power relationships: some outputs from a MAB Project on the island of Ouessant. Society and Natural Resources, 22(2), 172-188

Lewan L., Söderqvist T., 2002. Knowledge and recognition of ecosystem services among the general public in a drainage basin in Scania, Southern Sweden. Ecological economic, 42, 459-467

Martinez de Anguita P., Alonso E., Angelès Martin M., 2008. Environmental economic, political and ethical integration in a common decision-making framework. Journal of Environmental Management, 88, 154-164

Mazouni N., Rey-Valette H., 2008. Appui à l'élaboration d'indicateurs territoriaux de la GIZC dans une logique d'intégration et de partage des connaissances. Communication au colloque international pluridisciplinaire. Le littoral Subir, Dire, Agir, Lille 16-18 janvier 2008, p. 9

MEDDE, 2013. Les 9 défis de la Stratégie Nationale de Développement Durable 2010-2013 :“ Vers une économie verte et équitable ", 4 p (http://www.developpement-durable.gouv.fr/-Les-9-defis-.html) 
Mendoza G.A., Prahbu R., 2000. Development of a Methodology for Selecting Criteria and Indicators of Sustainable Forest Management: A Case Study on Participatory Assessment. Environmental Management 26(6), pp. 659-673

Merceron S., 2014. Bilan démographique de 2013. Points forts de la Polynésie française (n8). Institut de Statistique de la Polynésie Française

Millennium Ecosystem Assessment, 2005. Ecosystems and human well-being: current state and trends. Findings of the condition and trends working group of the Millennium Ecosystem Assessment. Island press, Washington, D.C., p. 815

O’Connor C., Marvier M., Kareiva P., 2003. Biological vs. social, economic and political prioritysetting in conservation. Ecology Letters, 6, 706-711

Pavlikakis G.E., Tsihrintzis V.A., 2003. A quantitative method for accounting human opinion, preferences and perceptions in ecosystem management. Journal of Environmental Management $68,193-205$

R Core Team., 2014. R: A language and environment for statistical computing. R Foundation for Statistical Computing, Vienna, Austria. www.r-project.org

Raux P., Bailly D., 2000. Etude socioéconomique de la perliculture en Polynésie française, "Situations des exploitants et des exploitations", Programme Général de Recherche sur la Nacre (PGRN2), Territoire de Polynésie française, OÏKOS, 112p

Reed M.S., Dougill A. J., Baker T. R., 2008. Participatory indicator development: what can ecologists and local communities learn from each other. Ecological Applications, 18(5), 1253-1269

Renning K., 2000. Redefining innovation. Eco-innovation research and the contribution from Ecological Economics. Ecological Economics, n³2, 319-332

Rey-Valette H., Clément O., Mathé S., Lazard J., Chia E., 2010. Quelques postulats relatifs aux indicateurs de développement durable : l'exemple de l'aquaculture. Natures, Sciences et Sociétés, $18,253-265$

Rey-Valette H., Clement O., Aubin J., Mathé S., Chia E., Legendre M., Caruso D., Mikolasek O., Blancheton J.P., Slembrouck J., Baruthio A., René F., Levang P., Morrissens P., Lazard J., 2008. Guide to the co-construction of sustainable development indicators in aquaculture. (C) Cirad, Ifremer, INRA, IRD, Université Montpellier 1. Diffusion Cirad-Montpellier, p. 144

Rey-Valette H., Laloë F., Le Fur J., 2007. Introduction to the key issue concerning the use of sustainable development indicators. International Journal of Sustainable Development 10 (1-2), 413

Schnapper D., 1996. La compréhension sociologique : démarche de l'analyse typologique. Presses Universitaires de France. Paris 
Talvard C., 2015. Bilan, La perle en 2013. Points Forts de la Polynésie Française, Institut de la Statistique de la Polynésie Française, p. 6

Thompson S.C., Stoutemeyer K., 1991. Water use as a commons dilemma: The effects of education that focuses on long-term consequences and individual action. Environment and Behavior. 23, 314333

Tisdell C., Poirine B., 2000. SPC Pearl Oyster Information Bulletin (14).

Torre A., Traversac J.B. (eds), 2011. Territorial Governance. Local Development, Rural Areas and Agrofood Systems, Springer Verlag, Heidelberg \& N. York

Vinck D., 2000. Approches sociologiques de la cognition et prise en compte des objets intermédiaires. $7^{\circ}$ école d'été de 1'ArCo Bons 10-21 juillet 2000

Weber M., 1992. L'objectivité de la connaissance. In Essais sur la théorie des sciences. Pocket Agora, Paris 